\title{
Voriconazole-induced periostitis
}

\author{
Christine Rossier • Vincent Dunet • Frederic Tissot • \\ Berengère Aubry-Rozier • Olivier Marchetti • \\ Ariane Boubaker
}

Received: 4 June 2011 / Accepted: 17 August 2011 / Published online: 6 September 2011

(C) Springer-Verlag 2011

We report the case of a 42-year-old woman receiving voriconazole for a fungal endophthalmitis, who presented with diffuse and severe musculoskeletal pain after 4 months of therapy. In the absence of an obvious aetiology, the patient was referred for three-phase bone scintigraphy. The anterior wholebody scan acquired $20 \mathrm{~min}$ after injection showed multiple and intense linear-shaped foci throughout the skeleton affecting predominantly the diaphyses of the long bones (a), corresponding to increased tracer uptake in the cortical bone on the delayed anterior whole-body scan affecting the upper and lower limbs, clavicles, scapulas and ribs $(\mathbf{b}, \mathbf{c})$.

In a recent case series of transplant recipients receiving long-term voriconazole therapy, a painful periostitis was associated with fluoride excess [1]. Wang et al. [2] reported a series of five patients with possibly drug-induced periostitis associated with voriconazole administration. These patients presented clinically with "secondary hypertrophic osteoarthropathy", a syndrome usually characterized by digital

C. Rossier $\cdot$ V. Dunet $\cdot$ A. Boubaker

Department of Nuclear Medicine,

CHUV and University of Lausanne,

Lausanne, Switzerland

F. Tissot $\cdot$ O. Marchetti

Department of Medicine, Infectious Diseases Service,

CHUV and University of Lausanne,

Lausanne, Switzerland

B. Aubry-Rozier

Center of Bone Diseases, CHUV and University of Lausanne,

Lausanne, Switzerland

\section{Rossier $(\bowtie)$}

Department of Nuclear Medicine, CHUV,

Rue du Bugnon 46,

CH-1011 Lausanne, Switzerland

e-mail: Christine.Rossier@chuv.ch clubbing, diffuse periostosis of the tubular bones and synovial effusions [3]. In our patient, a nodular periostitis and only a slight focal lamellar periosteal reaction around the radial and pretibial diaphyses were observed on review of the scintigraphy-guided conventional radiograph.

As this severe adverse event was probably associated with voriconazole, therapy was promptly stopped. Five days after discontinuation, all clinical symptoms had resolved and the radiographic anomalies had decreased at the 4-month follow-up.

This case report illustrates the key role of three-phase bone scintigraphy for the investigation of patients with atypical skeletal symptoms.



Conflicts of interest None. 


\section{References}

1. Wermers RA, Cooper K, Razonable RR, Deziel PJ, Whitford GM, Kremers WK, et al. Fluoride excess and periostitis in transplant patients receiving long-term voriconazole therapy. Clin Infect Dis. 2011;52:604-11.
2. Wang TF, Wang T, Altman R, Eshaghian P, Lynch JP 3rd, Ross DJ, et al. Periostitis secondary to prolonged voriconazole therapy in lung transplant recipients. Am J Transplant. 2009;9:2845-50.

3. Martinez-Lavin M, Pineda C. Hypertrophic osteoarthropathy. In: Hochberg MC, Silman AJ, Smolen JS, Weinblatt ME, Weisman MH, editors. Rheumatology. London: Mosby; 2003. p. 1763. 